\title{
Area-selective Immobilization of Multi Enzymes by Using the Reductive Desorption of Self-assembled Monolayer
}

\author{
Daisuke OYAMATSU, Norihiro KANAYA, Yu HIRANO, Matsuhiko NISHIZAWA, \\ and Tomokazu MATSUE*
}

\begin{abstract}
Department of Biomolecular Engineering, Graduate School of Engineering, Tohoku University (07 Aramaki-Aoba, Sendai, 980-8579, Japan)
\end{abstract}

Received November 19, 2002 ; Accepted February 3, 2003

\begin{abstract}
The immobilization of two enzymes on a pair of $\mathrm{Au}$ microband electrodes was performed by using electrochemical desorption of self-assembled monolayer (SAM) of alkanethiol. Both of the Au electrodes were coated with the SAM of n-octadecanethiol (ODT-SAM) at first. The ODT-SAM on one of the Au electrodes was electrochemically removed by applying reductive potential. The resulting naked Au surface was re-coated with the SAM of 2-aminoethanethiol (AET). These treatments resulted in a couple of Au electrodes coated with the ODT-SAM and AET-SAM, respectively. Horseradish peroxidase (HRP) was selectively immobilized on the AET-SAM by using crosslinking agent, glutaraldehyde. On the other hand, diaphorase (Dp) was immobilized on the surface of ODT-SAM by hydrophobic interaction. The imaging of the resulting substrate with scanning electrochemical microscope (SECM) demonstrated the enzymatic activities of HRP and Dp at the AET- and ODT- treated Au electrodes, respectively.
\end{abstract}

Key Words : Self-assembled Monolayer, Reductive Desorption, Enzyme, Immobilization

\section{Introduction}

The development of bio-devices using proteins has received much attention in advanced biotechnology. Among the various requirements for the preparation of bio-device, two-dimensional control of the protein distribution is of particular importance for the integration of biomolecules.

The formation of a self-assembled monolayer (SAM) of thiol molecules on the noble metal electrode such as $\mathrm{Au}, \mathrm{Ag}$ and $\mathrm{Cu}$ provides useful means for designing electrode surfaces with specified functionalities such as redox and electrocatalytic activities. ${ }^{1-14)}$ Proteins can easily be covalently immobilized at SAMs with functional groups such as $-\mathrm{NH}_{2}$ or $-\mathrm{COOH}$.

In this paper, we report a method for the selective immobilization of different enzymes, HRP and Dp, by using electrochemical desorption of SAMs as a key step. HRP is commonly used as a label enzyme for the bio-assay such as enzyme-linked immunosorbent assays (ELISA). Dp is used in this study because it can be immobilized on alkanethiols by hydrophobic interaction keeping high enzymatic activity. The resulting substrates were characterized by a SECM. SECM is capable of detecting the electrochemical redox reactions catalyzed by enzymes with extremely high sensitivity, thus affords information on the activity of the patterned enzymes.

\section{1 Chemicals}

\section{Experimental}

Dp purified from Bacillus stearothermophilus (EC 1.6. 99.-) was purchased from Unitika, Ltd. This enzyme has a molar mass of about 30,000 and has one flavin mononucleotide (FMN) as an electroactive site per molecule. ${ }^{15)}$
HRP was purchased from Funakoshi Co., Ltd. Ferrocenemethanol (FMA) was purchased from the Aldrich Chem. Co. and recrystallized from hexane. All other chemicals including the $25 \%$ glutaraldehyde solution (GA, Wako Pure Industries, Ltd.) and $\beta$-nicotinamide-adenine dinucleotide, the reduced form $(\mathrm{NADH}$, Orient Yeast Co., Ltd.), were used as received. All the solutions were prepared using the water purified with a Milli-Q II System (Millipore Co.).

\section{2 SECM measurements}

The microelectrodes used in the SECM measurements were prepared by sealing a Pt wire into a glass capillary, followed by polishing on a turntable (Narishige, Model EG-6) to give a disk-type microelectrode. The Au array electrode was prepared on a slide glasses by conventional photolithography method. The microelectrode was scanned with an XYZ stage (Chuo Seiki, LM-641-2 AE 1) equipped with three motor-driven actuators (Chuo Seiki, AME-15). These actuators were controlled by a stage controller (Chuo Seiki, M 9103). The electrochemical measurement was conducted with two electrodes system using the $\mathrm{Ag} \mid \mathrm{AgCl}$ (sat. $\mathrm{KCl}$ ) as the reference electrode. The current signal at the microelectrode was monitored with a current amplifier (KEITHLEY 427) and converted to digital data using a 16 bit $\mathrm{AD} / \mathrm{DA}$ board (Interface AZI-3506).

\section{Results and Discussion}

The schematic diagram of the immobilization of Dp and HRP is shown in Fig. 1. The array of " $\mathrm{D}$ " and "H"shaped electrodes (Fig. 1(a)) were immersed into an ethanol solution containing $10 \mathrm{mmol} \mathrm{dm}^{-3}$ ODT for two hours. As a result, these electrodes were coated with the 
(a)

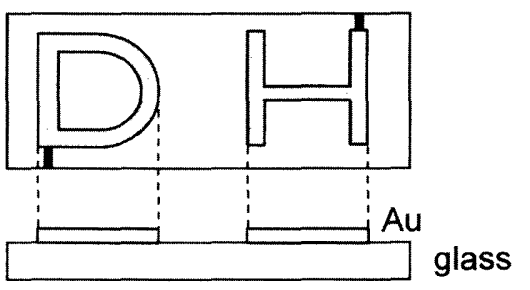

(b)

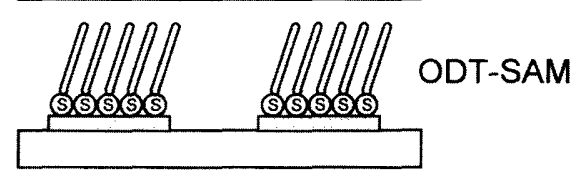

(c)

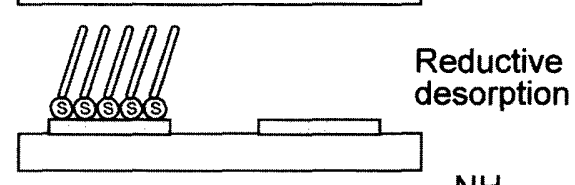

(d)

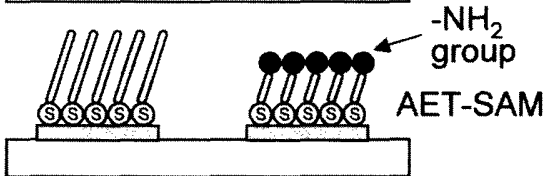

(e)
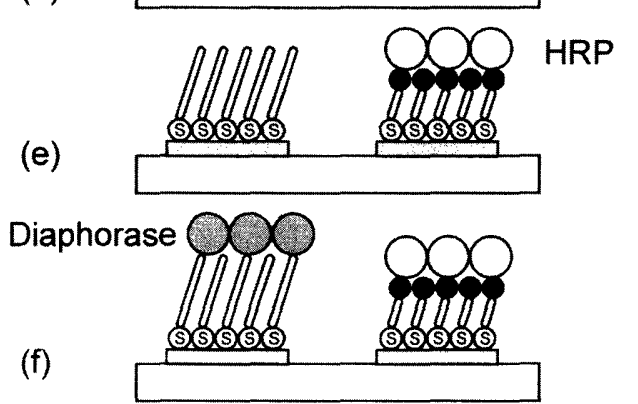

Fig. 1 Schematic diagram of the area-selective immobilization of Dp and HRP by using the reductive desorption of SAM.
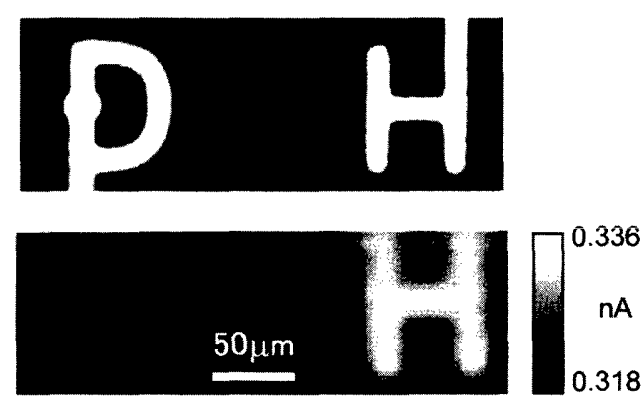

Fig. 2 (a) Photograph and (b) SECM image of the substrate after conducting the reductive desorption of ODT-SAM from the " $\mathrm{H}$ "-shaped electrode. Image size: $400 \times 100 \mu \mathrm{m}$. Scan rate of the microelectrode: $9.8 \mu \mathrm{m} \mathrm{s}^{-1}$. Electrode potential: + $0.5 \mathrm{~V}$ vs. $\mathrm{Ag} \mid \mathrm{AgCl}$. Electrolyte solution: $0.1 \mathrm{~mol} \mathrm{dm}^{-3} \mathrm{Na}_{2}$ $\mathrm{HPO}_{4}, 0.1 \mathrm{~mol} \mathrm{dm}^{-3} \mathrm{KCl}$ and $0.5 \mathrm{mmol} \mathrm{dm}{ }^{-3} \mathrm{FMA}$.

ODT-SAM (Fig. 1(b)). The ODT-SAM on the " $\mathrm{H}$ "-shaped electrode was desorbed by applying the potential of -1.9 $\mathrm{V}$ vs. $\mathrm{Ag} \mid \mathrm{AgCl}$ in an aqueous solution containing 0.1 mol dm ${ }^{-3} \mathrm{KOH}$ and $0.1 \mathrm{~mol} \mathrm{dm}{ }^{-3} \mathrm{KCl}$. After conducting the reductive desorption of ODT-SAM, the polarization was stopped and the resulting substrate was observed by $\mathrm{SECM}$. The microelectrode was polarized at $0.5 \mathrm{~V}$ vs. $\mathrm{Ag}$ $\mathrm{AgCl}$ and microelectrode-substrate distance was set to $5 \mu \mathrm{m}$. In the SECM image shown in Fig. 2, no current response was observed at the position of the " $\mathrm{D}$ "-shaped

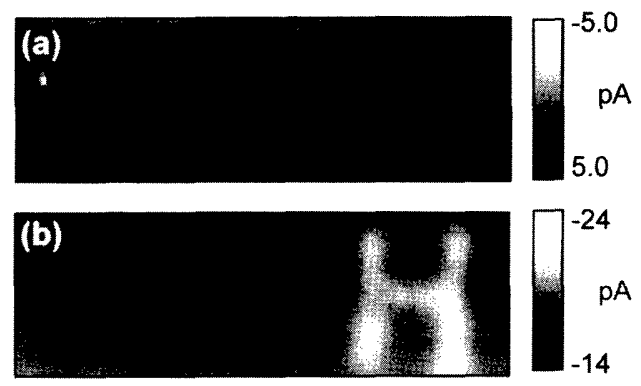

Fig. 3 SECM images in the absence (a) and the presence (b) of $0.5 \mathrm{mmol} \mathrm{dm}{ }^{-3} \mathrm{H}_{2} \mathrm{O}_{2}$ for the substrate prepared by the procedures shown in Fig. 1. The potential of the microelectrode was set at $0.05 \mathrm{~V}$ vs. $\mathrm{Ag} \mid \mathrm{AgCl}$. Image size: $400 \times 100$ $\mu \mathrm{m}$. Scan rate of the microelectrode: $9.8 \mu \mathrm{m} \mathrm{s}^{-1}$. Electrolyte solution: $0.1 \mathrm{~mol} \mathrm{dm}^{-3} \mathrm{Na}_{2} \mathrm{HPO}_{4}, 0.1 \mathrm{~mol} \mathrm{dm}^{-3} \mathrm{KCl}$ and 0.5 mmol dm ${ }^{-3}$ FMA.

electrode. On the other hand, the oxidation current was significantly increased for the " $\mathrm{H}$ "-shaped electrode. When the microelectrode above the metal surface is polarized at $0.5 \mathrm{~V}$ vs. $\mathrm{Ag} \mid \mathrm{AgCl}$, FMA is oxidized at the microelectrode surface. Thus the local concentration ratio of $\mathrm{FMA}^{+}$to FMA near the microelectrode becomes different from that at other substrate areas. This concentration difference induces a so-called "local battery", ensuring the continuous redox cycling between the microelectrode and the metal substrate, even though the metal substrate is disconnected from the external power supply. The results shown in Fig. 2 indicate that ODT-SAM has the strong blocking effect to the permeation of the FMA to the $\mathrm{Au}$ electrode surface, and ODT molecules are desorbed from the " $\mathrm{H}$ "-shaped Au electrode by the reductive desorption.

After conducting the reductive desorption of ODTSAM, the substrate was thoroughly rinsed with pure water and immersed into an aqueous solution containing $10 \mathrm{mmol} \mathrm{dm}^{-3}$ AET for two hours (Fig. 1(d)) to modify the naked " $\mathrm{H}$ "-shaped electrode with AET-SAM. After rinsing with pure water, the substrate was immersed into an aqueous solution containing the $1 \%$ glutaraldehyde. The HRP was then immobilized only on the " $\mathrm{H}$ "-shaped electrode as illustrated in Fig. 1 (e). Finally, Dp was immobilized on the "D"-shaped electrode coated with ODTSAM by hydrophobic interaction (Fig. 1(f)).

Figure 3 shows the SECM images of the substrate prepared by the procedures shown in Fig. 1. Images were taken at $0.05 \mathrm{~V}$ vs. $\mathrm{Ag} \mid \mathrm{AgCl}$ in an electrolyte solution containing $0.5 \mathrm{mmol} \mathrm{dm}^{-3}$ FMA in the absence (a) and the presence (b) of $0.5 \mathrm{mmol} \mathrm{dm}{ }^{-3} \mathrm{H}_{2} \mathrm{O}_{2}$. In the presence of $\mathrm{H}_{2} \mathrm{O}_{2}$, the reduction current was significantly increased on the " $\mathrm{H}$ "-shaped electrode from that in the absence of $\mathrm{H}_{2} \mathrm{O}_{2}$, since the HRP immobilized on the " $\mathrm{H}$ "shaped electrode oxidized FMA to $\mathrm{FMA}^{+}$. It reveals that the HRP was immobilized with maintaining its activity. On the other hand, no current response was observed on the " $\mathrm{D}$ "-shaped electrode, indicating that the undesired immobilization of HRP on the "D"-shaped electrode does not occur.

Figure 4 shows the SECM images of the same sub- 

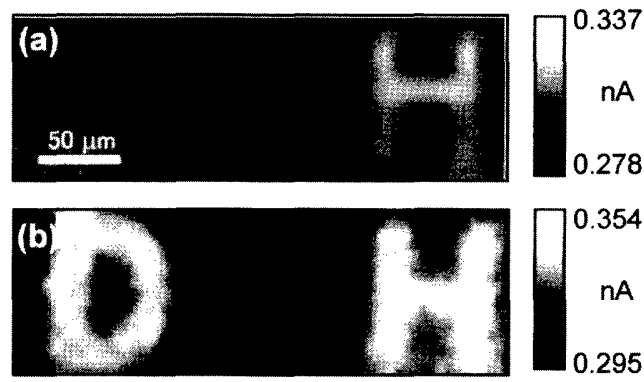

Fig. 4 SECM images in the absence (a) and the presence (b) of $5 \mathrm{mmol} \mathrm{dm}{ }^{-3} \mathrm{NADH}$ of the same substrate in Fig. 3. The potential of the microelectrode was set at $0.5 \mathrm{~V}$ vs. $\mathrm{Ag}$ | $\mathrm{AgCl}$. Image size: $400 \times 100 \mu \mathrm{m}$. Scan rate of the microelectrode : $9.8 \mu \mathrm{m} \mathrm{s}^{-1}$. Electrolyte solution: $0.1 \mathrm{~mol} \mathrm{dm}^{-3} \mathrm{Na}_{2}$ $\mathrm{HPO}_{4}, 0.1 \mathrm{~mol} \mathrm{dm}{ }^{-3} \mathrm{KCl}$ and $0.5 \mathrm{mmol} \mathrm{dm}{ }^{-3} \mathrm{FMA}$.

strate as that in Fig. 3, but at $0.5 \mathrm{~V}$ vs. $\mathrm{Ag} \mid \mathrm{AgCl}$ in an electrolyte solution containing $0.5 \mathrm{mmol} \mathrm{\textrm {dm } ^ { - 3 }} \mathrm{FMA}$ in the absence (a) and the presence (b) of $5 \mathrm{mmol} \mathrm{dm}^{-3}$ NADH. The slightly larger oxidation current at the " $\mathrm{H}$ "shaped electrode (Fig. 4(a)) is due to the redox cycling reaction of FMA between the microelectrode and the "H"-shaped electrode thorough the loosely packed AETSAM. In the presence of NADH (Fig. 4(b)), the oxidation current at the "D"-shaped electrode was greatly increased. Dp can reduce the oxidized form of FMA, resulting in the increase in the oxidation current by the catalytic redox cycling. ${ }^{\prime \prime}$ This result reveals that the $\mathrm{Dp}$ is immobilized at the " $\mathrm{D}$ "-shaped electrode with maintaining its activity. However, the oxidation current was also increased at the " $\mathrm{H}$ "-shaped electrode. This result suggests that some Dp molecules also exist at the " $\mathrm{H}$ "shaped electrode. It would be due to the reaction of Dp molecules with the excess aldehyde group at the " $\mathrm{H}$ "shaped electrode. This problem would be solved by the treatment of the excess aldehyde group with aminofunctionalized molecules such as alkyl amines.

In conclusion, selective immobilization of Dp and HRP was performed by using the electrochemical desorption of SAM of thiol as a key procedure. SECM imaging of a Dp and HRP-patterned substrate demonstrated that these enzymes were locally immobilized with maintaining their activities. The method reported here can be widely used for fabrication of biodevices with an array of proteins such as enzymes and antibodies. It is known that the two-dimensional phase separation of SAM takes place when the binary SAM was formed from the solution containing two types of thiol molecules. ${ }^{17,18)}$ Since the desorption potential of thiol SAM varies depending on the length of alkyl chain or type of terminal functional group, ${ }^{19)}$ such the phase separation phenomena would be used as the template fabrication of protein nanoarrays.

\section{Acknowledgements}

This work was supported by a Grant-in-Aid for Priority Area 417 (No. 14050010) and a Grant-in-Aid for the Creation of Innovations through Business-Academic-Public Sector Cooperation (No. 13504) from the Ministry of Education, Culture, Sports, Science and Technology, Japan.

\section{References}

1) A. J. Bard, H. D. Abruña, C. E. Chidsey, L. R. Faulkner, S. W. Feldberg, K. Itaya, M. Majda, O. Melroy, R. W. Murray, M. D. Porter, M. P. Soriaga, and H. S. White, J. Phys. Chem., 97, 7147 (1993).

2) H. O. Finklea, in: A. J. Bard and I Rubinstein (Eds.), Electroanalytical Chemistry, Vol.19, Marcel Dekker: New York, Basel, Hong Kong, Chap. 2 (1996).

3) R. L. Bretz and H. D. Abruna, J. Electroanal. Chem., 408, 199 (1996).

4) J. Redepenning and J. M. Flood, Langmuir, 12, 508 (1996).

5) H. O. Finklea, L. Liu, M. S. Ravenscroft, and S. Punturi, J. Phys. Chem., 100, 18852 (1996).

6) Z. Liu, J. Li, S. Dong, and E. Wang, Anal. Chem., 68, 2432 (1996).

7) J. D. Green, M. T. McDermott, and M. D. Porter, J. Phys. Chem., 100, 13342 (1996).

8) K. Bandyopadhyay, M. Sastry, V. Paul, and K. Vijayamohanan, Langmuir, 13, 866 (1997).

9) J. Li, J. Yan, Q. Deng, G. Cheng, and S. Dong, Electrochim. Acta, 42, 961 (1997).

10) H. O. Finklea and D. D. Handhew, J. Electroanal. Chem., 347, 327 (1993).

11) D. Oyamatsu, M. Nishizawa, S. Kuwabata, and H. Yoneyama, Langmuir, 14, 3298 (1998).

12) D. Oyamatsu, S. Kuwabata, and H. Yoneyama, J. Electroanal. Chem., 473, 59 (1999).

13) S. Kuwabata, H. Kanemoto, D. Oyamatsu, and H. Yoneyama, Electrochemistry, 67, 1254 (1999).

14) D. Oyamatsu, H. Kanemoto, S. Kuwabata, and H. Yoneyama, J. Electroanal. Chem., 497, 97, (2001).

15) T. Matsue, H. Yamada, H. Chang, and I. Uchida, Bioelectrochem. Bioenerg., 25, 347 (1990).

16) D. Oyamatsu, N. Kanaya, H. Shiku, M. Nishizawa, and T. Matsue, Sensors and Actuators B. in press.

17) M. Nishizawa, T. Sunagawa, and H. Yoneyama, J. Electroanal. Chem., 436, 213 (1997).

18) D. Hobara, M. Ota, S. Imabayashi, K. Niki, and T. Kakiuchi, J. Electroanal. Chem., 444, 113 (1998).

19) C. A. Widrig, C. Chung, and M. D. Porter, J. Electroanal. Chem., 310, 335 (1991). 